ВЕСТНИК НПУА. МЕТАЛЛУРГИЯ, МАТЕРИАЛОВЕДЕНИЕ, НЕДРОПОЛЬЗОВАНИЕ. 2021. №1 УДК 669.046.462

МЕТАЛЛУРГИЯ

DOI: 10.53297/18293395-2021.1-9

\title{
ИЗУЧЕНИЕ МЕХАНИЗМА И КИНЕТИКИ ВОССТАНОВЛЕНИЯ КОНЦЕНТРАТОВ ГЕМАТИТА С УГЛЕРОДОМ И КАРБОНАТОМ НАТРИЯ
}

\author{
А.М. Оганесян ${ }^{1}$ Т.А. Демирчян ${ }^{2}$, Алла С. Агбалян ${ }^{1}$ \\ ${ }^{1}$ Национальный политехнический университет Армении \\ 23АО "Русал Арменал"
}

Теоретическими расчетами обоснованы и экспериментальным методом доказаны механизм и кинетика восстановления гематитовых концентратов углеродом и карбонатом натрия. Согласно описанному механизму, в присутствии $10 \%$ соды резко ускоряется процесс восстановления, а углерод является лучшим восстановителем для гематитового концентрата. Показано, что сода активирует процесс газификации углерода продуктами деления $\left(\mathrm{Na}_{2} \mathrm{CO}_{3} \rightarrow \mathrm{Na}_{2} \mathrm{O}+\mathrm{CO}_{2}\right)$, которые сохраняют избыточную энергию и вводятся в кристаллическую решетку графита, помогая ослабить связи между базовыми плоскостями. Сода также влияет на извлечение магнетита, на поверхности которых адсорбируются возбужденные молекулы $\mathrm{Na}_{2} \mathrm{O}$. В этом случае добавление соды к одновалентному металлу способствует изменению количества свободных электронов или дырок, в результате чего изменяются также реакционные свойства оксида.

Выявлено, что при температуре $500{ }^{\circ} \mathrm{C}$ практически не происходит взаимодействия карбоната натрия с оксидом железа, а при температуре $700{ }^{\circ} \mathrm{C}$ реакция оксида железа с содой протекает очень интенсивно, в результате чего образуется феррит натрия. Однако в восстановительной среде при температуре $500 . .600{ }^{\circ} \mathrm{C}$ оксиды железа восстанавливаются до низших оксидов, а при более высокой температуре - до металлического железа.

Процесс обжига изучен методом дериватографического анализа, в результате которого были выбраны следующие оптимальные режимы обжига: $\mathrm{T}_{\mathrm{o}}=1000 \ldots 1050{ }^{\circ} \mathrm{C}$, $\tau_{0}=2,5 \ldots 3,0$ ч. Установлено, что роль соды заключается не только в интенсификации образования и восстановления силиката, но и в уменьшении производительности процесса на $20 \%$ и снижении температуры восстановления на $130 \ldots 150{ }^{\circ} \mathrm{C}$. Показано, что твердофазные реакции образования силикатов в восстановленной смеси при температуре $700 \ldots 1100{ }^{\circ} \mathrm{C}$ приводят к образованию водорастворимых соединений, которые легко удаляются влажной магнитной сепарацией.

Ключевые слова: гематитовый концентрат, углерод, карбонат натрия, обжиг, фаза, преобразование, процесс силикатообразования, восстановление.

Введение. Республика Армения, располагающая месторождениями черных, цветных, редких и драгоценных металлов, запасы которых не очень 
велики, высоко оценивает возможности комплексного использования полезных ископаемых и концентратов для создания безотходного производства, в том числе и возможности извлечения железа, которое необходимо для производства не только стали, но и порошковых сплавов.

Относительно высокая стоимость металлических порошков и трудности их транспортировки существенно затрудняют производство металлокерамических изделий и их внедрение в различные отрасли народного хозяйства, тогда как в мировой практике в последние годы использование металлических порошков в производстве различных порошковых композиционных материалов значительно расширилось. При изготовлении металлических порошков особое место уделяется железному порошку, на основе которого для различных машин и оборудования изготавливается большое количество деталей.

Поскольку в настоящее время ввоз металлического порошка в республику из стран СНГ почти прекращен, то возникла острая необходимость организовать их производство на базе местного сырья. Это связано с тем, что Армения довольно богата железными месторождениями и уже разработаны соответствующие технологии получения из них богатых концентратов. С этой точки зрения работа актуальна и перспективна.

Постановка задачи и обоснование методики. Исходя из вышеизложенного, целью работы является изучение кинетики и механизма восстановления гематитовых концентратов углеродом и карбонатом натрия.

В качестве исходных материалов были выбраны минералы железных руд Армении, минералогический состав которых представлен в таблице. Из них промышленное значение имеют Капутанское месторождение апатитмагнетитовых руд (запасы 200 млн $m$ ), Сваранское месторождение титаномагнетитовых руд (запасы $800 \ldots 1000$ млн $m$ ) и Разданский магнетитовый рудник (запасы 250...300 млн $m$ ) [1].

Были выбраны и обоснованы технологические процессы получения железного порошка, методика исследования структуры и свойств, в том числе силикатообразующих реакций, методы дифференциально-термического и рентгеноструктурного анализа (DTA и PCA). Методами PCA и DTA были исследованы кинетика и механизмы восстановления железорудных концентратов $\left(20 \ldots 1200^{\circ} \mathrm{C}\right)$.

Однородность распространения элементов по объему и химическому составу определялась методом микроспектрального анализа с использованием рентгеновского микроанализатора JXA-5 (фирма JOUL, Япония), а кинетические процессы исследовались с использованием дериватографа, с помощью 
которого электронный шестиканальный самописец в микровольтном диапазоне одновременно регистрирует температуру (T), массу (TG), скорость изменения массы (DTG) и теплоемкость исследуемого вещества в зависимости от температуры или времени (DTA - от комнатной до $600^{\circ} \mathrm{C}$ ).

Таблица

Процентное содержание железа и минералов в месторождениях Армении, \%

\begin{tabular}{l|c|c|c|c}
\hline Компоненты & $\begin{array}{l}\text { Капутанское } \\
\text { месторож- } \\
\text { дение }\end{array}$ & $\begin{array}{l}\text { Сваранское } \\
\text { месторож- } \\
\text { дение }\end{array}$ & $\begin{array}{l}\text { Разданское } \\
\text { месторож- } \\
\text { дение }\end{array}$ & $\begin{array}{l}\text { Кохбайское } \\
\text { месторож- } \\
\text { дение }\end{array}$ \\
\hline $\mathrm{Fe}$ & 55,4 & 20,5 & 32,70 & 31,58 \\
$\mathrm{FeO}$ & 22,91 & 6,38 & 5,10 & 13,98 \\
$\mathrm{Fe}_{2} \mathrm{O}_{3}$ & 53,63 & 23,62 & 40,56 & 38,90 \\
$\mathrm{SiO}_{2}$ & 5,69 & 26,75 & 26,50 & 29,44 \\
$\mathrm{Al}_{2} \mathrm{O}_{3}$ & 2,10 & 3,08 & 4,40 & 8,29 \\
$\mathrm{CaO}$ & 5,49 & 0,73 & 18,30 & 4,27 \\
$\mathrm{MgO}$ & 1,36 & 25,20 & 1,40 & 1,54 \\
$\mathrm{MnO}$ & 0,14 & 0,50 & 0,54 & 0,24 \\
$\mathrm{P}_{2} \mathrm{O}_{5}$ & 5,72 & 0,02 & 0,05 & 0,30 \\
$\mathrm{TiO}_{2}$ & 0,57 & 0,92 & 0,30 & 0,17 \\
$\mathrm{~V}_{2} \mathrm{O}_{5}$ & 0,16 & 0,08 & 0,07 & 0,03 \\
$\mathrm{Na}_{2} \mathrm{O}$ & 0,08 & - & 0,026 & - \\
$\mathrm{K}_{2} \mathrm{O}$ & 0,07 & - & 0,36 & - \\
$\mathrm{S}$ & 0,05 & 0,08 & 0,02 & 1,57 \\
$\mathrm{Te}$ & 0,0002 & - & 0,0002 & - \\
\hline
\end{tabular}

Микроструктура порошка железа исследовалась на нетравленых и травленых образцах, где в качестве травителя были взяты $1 \%$ пикриновая кислота - 22 г, $\mathrm{HNO}_{3}-2 \ldots 4$ мл, этиловый спирт -100 мл, 2\% едкого натрия - 25 г, 2 г пикриновой кислоты, вода - 100 мл. Структурный анализ проводился с помощью оптических HEOFOT-21 и электронных РЭМ-200 микроскопов. Фазовый состав исследовался с помощью рентгеновского дифрактометра ДРОН-2,0 с CmKr излучением.

Плотность порошкообразного вещества определялась путем изостатического взвешивания и микроскопической оценки порошка.

Твердость определялась методами Бринелля (ГОСТ 9012-95), Роквелла (ГОСТ 9013-95) и Виккерса (ГОСТ 2999-79), а микротвердость - микротвердомером типа ПМТ-3 (ГОСТ 945-76). 
Результаты исследования. Гематитовые руды после измельчения в барабанно-шаровых мельницах в жидкой среде [2] подвергались гравитационному обогащению, во время которого в качестве жидкости использовали воду. По результатам проведенного эксперимента после обогащения было удалено 20,1\% пустых пород, а оставшиеся 79,9\% осадка смешивались с твердым восстановителем (графит, ламповая сажа) $-4 . .5 \%$ по массе руды.

Была приготовлена шихта, после чего ее гранулировали, в качестве жидкости был использован 10\%-ный водный раствор соды. Таким образом, процесс гранулирования смеси был совмещен с процессом введения водного раствора соды в смесь, а не добавления в сухом состоянии. Это позволяет тяжелым частицам соды равномерно распределяться по всему объему смеси, вследствие чего ее активность резко увеличивается, и во время восстановления огарковой смеси получается мягкая и пористая губка в виде шара. Таким образом, создаются благоприятные условия для более эффективного процесса восстановления, а также для удаления отходов. Карбонат натрия позволяет одновременно проводить процессы восстановления и химического рафинирования шихты, т.е. происходит не только восстановление оксидов железа, но и химическое взаимодействие соды со смесью, образуя силикатное, алюминатное и другие растворимые соединения. Взаимодействие $\mathrm{Al}_{2} \mathrm{O}_{3}$ c содой начинается примерно при температуре $700^{\circ} \mathrm{C}$ [3]:

$$
\mathrm{Al}_{2} \mathrm{O}_{3}+\mathrm{Na}_{2} \mathrm{CO}_{3} \rightarrow \mathrm{Na}_{2} \mathrm{O} \cdot \mathrm{Al}_{2} \mathrm{O}_{3}+\mathrm{CO}_{2} \text {. }
$$

Вначале реакция проходит довольно медленно, но при повышении температуры она ускоряется, образуя металлоалюмосиликаты. Система $\mathrm{NaSiO}_{3}$ образует несколько силикатов натрия: $\mathrm{NaSiO}_{2}, \mathrm{Na}_{2} \mathrm{O} \cdot 2 \mathrm{SiO}_{2}, 2 \mathrm{Na}_{2} \mathrm{O} \cdot \mathrm{SiO}_{2}$. Реакция между диоксидом кремния и соды протекает интенсивно при температуре $800 \ldots 820^{\circ} \mathrm{C}$, образуя метасиликат натрия:

$$
\mathrm{SiO}_{2}+\mathrm{Na}_{2} \mathrm{CO}_{3} \rightarrow \mathrm{Na}_{2} \mathrm{O} \cdot \mathrm{SiO}_{2}+\mathrm{CO}_{2} \text {. }
$$

Исследуя взаимодействие диоксида кремния (кремнезема) и глинозёма с содой, выяснилось, что конечными соединениями являются метасиликат натрия и алюминат. При более высокой температуре реакция приводит к образованию алюмосиликата натрия $\left(\mathrm{Na}_{2} \mathrm{O} \cdot \mathrm{Al}_{2} \mathrm{O}_{3} \cdot 2 \mathrm{SiO}_{2}\right)$.

Соединения кальция, магния и марганца при спекании избыточной содой могут образовывать промежуточные карбонатные соли, которые при температуре $500^{\circ} \mathrm{C}$ начинают разлагаться, образуя легкорастворимые в кислотах оксиды. Оксид фосфора, взаимодействуя с содой, образует фосфорно-натриевую соль, которая растворяется в воде. Диоксид титана, взаимодействуя с содой, образует титанат натрия $\mathrm{Na}_{2} \mathrm{O} \cdot \mathrm{TiO}_{2} \cdot 2,5 \mathrm{H}_{2} \mathrm{O}$, который может быть преобразован из растворимой $\alpha$ модификации в трудно 
растворимую $\beta$ модификацию. Соединения хрома образуют растворимый хромат натрия $\mathrm{NaCrO}_{2}$. Соединения ванадия, вольфрама, молибдена и мышьяка также образуют растворимые натриевые соли: $\mathrm{Na}_{2} \mathrm{VO}_{4}, \mathrm{Na}_{2} \mathrm{WO}_{4}$, $\mathrm{Na}_{2} \mathrm{MoO}_{4}, \mathrm{Na}_{3} \mathrm{AsO}_{4}$.

Взаимодействия карбоната натрия с оксидом железа при температуре $500^{\circ} \mathrm{C}$ практически не происходит, а при температуре $700^{\circ} \mathrm{C}$ реакция оксида железа с содой протекает очень интенсивно, в результате чего образуется феррит натрия:

$$
\mathrm{Fe}_{2} \mathrm{O}_{3}+\mathrm{Na}_{2} \mathrm{CO}_{3} \rightarrow \mathrm{Na}_{2} \mathrm{O} \cdot \mathrm{Fe}_{2} \mathrm{O}_{3}+\mathrm{CO}_{2} .
$$

Однако в восстановительной среде при температуре $500 \ldots 600^{\circ} \mathrm{C}$ оксиды железа восстанавливаются до низших оксидов, а при более высокой температуре - до металлического железа. На рис. 1 представлена зависимость температуры и продолжительности восстановления смеси от количества соды. Видно, что при содержании до 5\% соды происходит резкое снижение температуры и продолжительности восстановления, а при содержании $10 \%$ соды температура восстановления смеси снижается на $130 \ldots 150{ }^{\circ} \mathrm{C}$, и период продолжительности восстановления сокращается на $20 \%$. Без соды чистота железного порошка смеси не бывает очень высокой, удаление примесей незначительно, а при содержании $10 \% \quad \mathrm{Na}_{2} \mathrm{CO}_{3}$ содержание железа увеличивается до $99,7 \%$ (рис. 2).

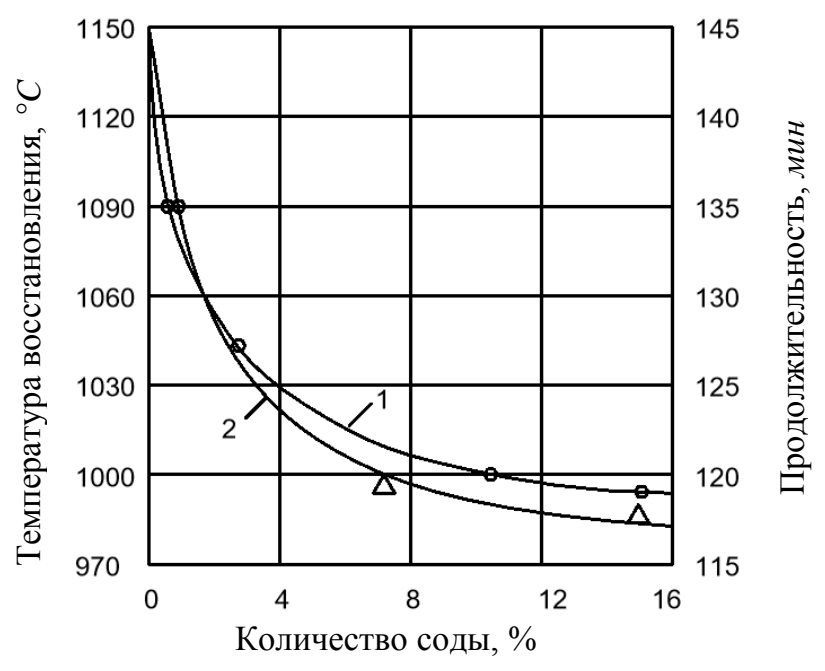

Рис. 1. Влияние соды на конечную температуру (кривая 1) и продолжительность (кривая 2) восстановления шихть 
Согласно результатам проведенных исследований, реакция $\mathrm{Fe}_{2} \mathrm{O}_{3} \rightarrow \mathrm{Fe}_{3} \mathrm{O}_{4}$ характеризуется экзотермическим и высоким свойством восстановления, в то время как реакция $\mathrm{Fe}_{3} \mathrm{O}_{4} \rightarrow \mathrm{FeO}$ эндотермическая, газовая фаза преобразовывается в $\mathrm{CO}_{2}$, а скорость восстановления снижается, минимальная скорость реакции соответствует $20 \ldots 25 \%$ степени восстановления, т.е. полному переходу $\mathrm{Fe}_{3} \mathrm{O}_{4} \rightarrow \mathrm{FeO}$.

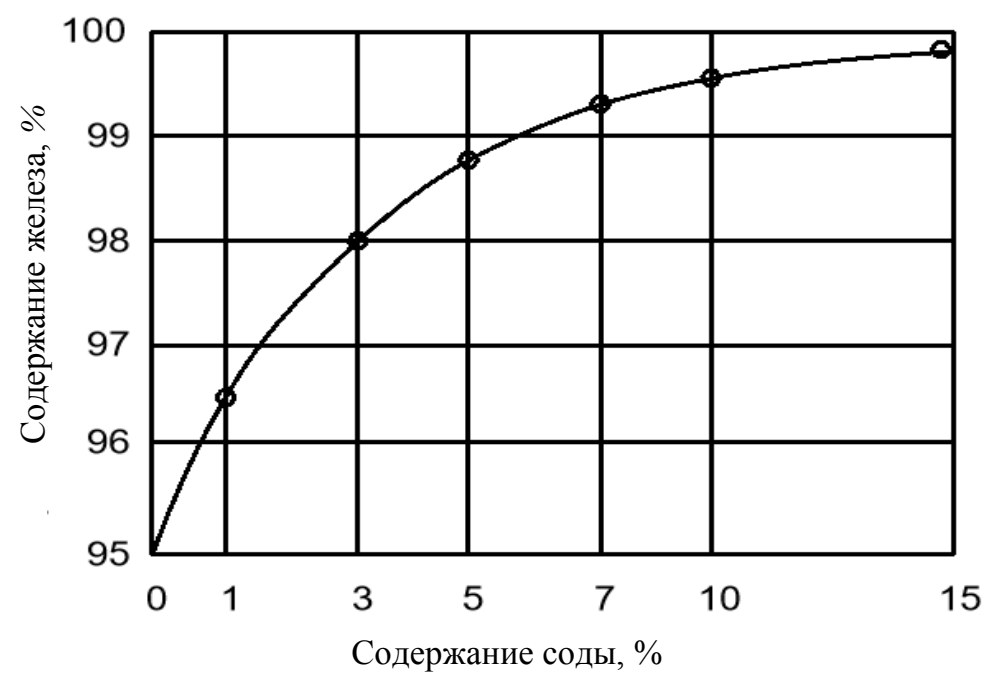

Рис. 2. Влияние рафинирования соды на чистоту железного порошка

На третьей стадии преобразования $\mathrm{FeO} \rightarrow \mathrm{Fe}$ сохраняется явление поглощения тепла, а содержание $\mathrm{CO}_{2}$ снижается, т.е. процесс реакции $\mathrm{C}+\mathrm{CO}_{2} \rightarrow 2 \mathrm{CO}$ становится более сложным. Это способствует увеличению скорости реакции $\mathrm{FeO} \rightarrow \mathrm{Fe}$. Сказанное объясняется каталитическим действием вновь образующегося $\mathrm{Fe}$ в результате газификации углерода $[4,5]$. Таким образом, имеет место активация коэффициента $\mathrm{C}+\mathrm{CO}_{2} \rightarrow 2 \mathrm{CO}$ за счет проникновения железа в кристаллическую решетку углерода и его набухания. Разложение СО газа происходит в последующих элементарных стадиях: 1) адсорбция газа от газовой фазы на поверхности катализатора $\mathrm{CO}_{\mathrm{r}} \rightarrow \mathrm{CO}_{\text {адс; }}$; 2) деление адсорбированной молекулы катализатором по реакции, которое в основном происходит из-за того, что расстояние между атомами железа больше, чем расстояние между С и О в молекуле $\mathrm{CO}$, кристаллическая решетка железа притягивает молекулу, ослабляя связь между С и О. Таким образом, атом С отделяется от молекулы СО, в результате чего концентрация кислорода в молекулах увеличивается; 3) десорбция $\mathrm{CO}_{2}$ в газовую атмосферу. В 
процессе получения железного порошка влияние рафинирования содой смеси возникает во время влажного магнитного обогащения, которое основано на магнитной восприимчивости порошковых частиц. Степень восстановления

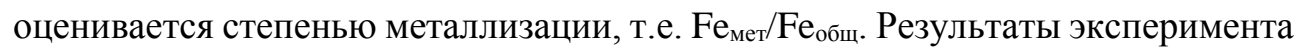
представлены на рис. 3. Можно увидеть, что углерод (ламповая сажа) обладает лучшими восстановительными свойствами. Таким образом, извлечение концентрата за 35 мин составляет $98 \ldots 98,5 \%$.

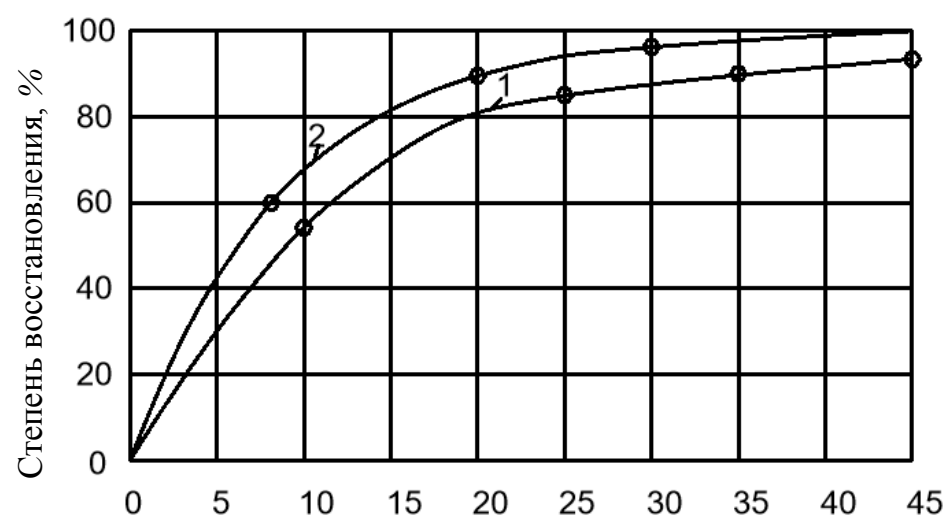

Рис. 3. Кинетика восстановления углеродного конщентрата $\left(1-1050^{\circ} \mathrm{C}, 2-1150^{\circ} \mathrm{C}\right)$

В процессе обжига частицы с диаметром 10 мм за час восстанавливаются на $100 \%$, причем начальная стадия протекает по химической кинетике, а конечная - по диффузионному механизму. Тип слоя также играет важную роль. Как показано на рис. 4, гранулированная смесь восстанавливается на $100 \%$ за 4,5 ч (линия 1), а в случае свободного наполнения смесь восстанавливается всего на $40 \%$ даже в течение 8 часов.

Состав шихты по массе составляет: 100 частей концентрата, 165 частей твердого углерода и 20 частей кальциевой соды. Количество соды определяется протеканием силикатообразующих реакций и добавляется в смесь 4 раза (размер частиц соды $0,5 \ldots 1$ мм) с целью получения водорастворимых соединений, таких как $\mathrm{Na}_{2} \mathrm{O} \cdot 2 \mathrm{SiO}, \mathrm{Na}_{2} \mathrm{O} \cdot \mathrm{Al}_{2} \mathrm{O}_{3}, \mathrm{CaCO}_{3}, \mathrm{MgCO}_{3}, \mathrm{MnCO}_{3}, \mathrm{Na}_{3} \mathrm{PO}_{4}$.

Проведены комплексные дериватографические исследования по восстановлению с помощью соды и углерода, а также по изучению кинетики. Температуру восстановления для шихты, содержащей $0 \ldots 15 \%$ соды, изучали при температуре $25 \ldots 1200^{\circ} \mathrm{C}$.

Эксперименты проводились на дериватографе DERIVATOGRAPH-C, результаты которых для образца, содержащего 5\% соды, показаны на рис. 5. 


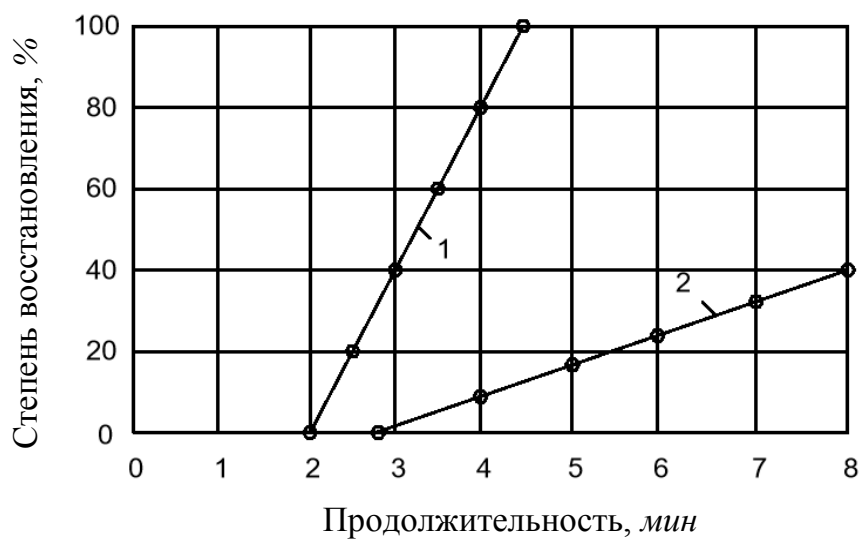

Рис. 4. Влияние типа слоя (10\% $\left.\mathrm{Na}_{2} \mathrm{CO}_{3}\right)$ на степень восстановления при $1050^{\circ} \mathrm{C}: 1$ - гранулированный слой (диаметр - 10 мм), 2 - слой при свободной засыпке (толщзина слоя - 60 мм)



Продолжительность, мин

Рис. 5. Дериватограмма шихты, содержащей 5\% $\mathrm{Na}_{2} \mathrm{CO}_{3}:$ 1,2,3,4 - coomветственно кривые при нагревании образиа по температуре (T), дифференциальному термическому анализу (DTA), изменению массы (TG) и скорости изменения массы (DTG), а 1',2',3',4' - соответственно кривые при охлаждении образиа 
Как видно из рис. 5 , первый минимум на дериватограмме образуется при температуре $\sim 130{ }^{\circ} \mathrm{C}$ и повторяется независимо от содержания соды. Процесс происходит при поглощении тепла и уменьшении навески образца, что объясняется выделением отсорбированной влаги. Следующий минимум также характерен для различных содержаний шихты и регистрируется с помощью кривых DTA и DTG при температуре $576 \pm 7^{\circ} \mathrm{C}$. Процесс протекает в интервале температур $540 \ldots 650^{\circ} \mathrm{C}$ и объясняется первой стадией восстановления: $\mathrm{Fe}_{2} \mathrm{O}_{3} \rightarrow \mathrm{Fe}_{3} \mathrm{O}_{4}$. Повышение температуры до $650 \ldots 790^{\circ} \mathrm{C}$ на кривой ДТА приводит к появлению нового минимума при $750^{\circ} \mathrm{C}$, что объясняется взаимодействием соды со смесями в концентрате:

$$
\begin{gathered}
\mathrm{Na}_{2} \mathrm{CO}_{3}+\mathrm{SiO}_{2} \rightarrow \mathrm{Na}_{2} \mathrm{SiO}_{3}+\mathrm{CO}_{2} \uparrow, \\
\mathrm{Na}_{2} \mathrm{CO}_{3}+\mathrm{Al}_{2} \mathrm{O}_{3} \rightarrow \mathrm{Na}_{2} \mathrm{Al}_{2} \mathrm{O}_{4}+\mathrm{CO}_{2} \uparrow .
\end{gathered}
$$

$\mathrm{B}$ то же время реакция второй стадии восстановления $\mathrm{Fe}_{3} \mathrm{O}_{4} \rightarrow \mathrm{FeO}$ ускоряется. Она осуществляется как по твердофазному механизму диффузии $\mathrm{Fe}_{3} \mathrm{O}_{4}+\mathrm{C} \rightarrow \mathrm{FeO}+\mathrm{CO}_{2} \uparrow$, так и по газофазному механизму $\mathrm{Fe}_{3} \mathrm{O}_{4}+\mathrm{CO} \rightarrow \mathrm{FeO}+$ $+\mathrm{CO}_{2} \uparrow$. 5\%-я концентрация соды соответствует стехиометрическому количеству компонентов, которого вполне достаточно для взаимодействия со смесями концентратов. В интервале температур $790 \ldots 900^{\circ} \mathrm{C}$ фиксируется этот минимум, что также относится к процессу $\mathrm{Fe}_{3} \mathrm{O}_{4} \rightarrow \mathrm{FeO}$ и, по-видимому, $\mathrm{FeO} \rightarrow \mathrm{Fe}$. Исследования показали, что с увеличением содержания соды скорость извлечения $\mathrm{Fe}_{3} \mathrm{O}_{4} \rightarrow \mathrm{FeO}$ и $\mathrm{FeO} \rightarrow \mathrm{Fe}$ увеличивается. Это объясняется взаимодействием смесей соды и приводит к обнаружению связанных оксидов железа. Третий этап восстановления $\mathrm{FeO} \rightarrow \mathrm{Fe}$ проходит при температуре $900 \ldots 1000^{\circ} \mathrm{C}$. Этот этап восстановления на дериватограммах объясняется экстремумом кривых DTA и DTG (при $970^{\circ} \mathrm{C}$ ), а кривые TG претерпевают изменение массовой скорости с определенной скоростью. До содержания 5\% соды наблюдается резкое снижение конечной температуры восстановления. Для $10 \%$ содовой смеси конечная температура восстановления на $130 \ldots 150^{\circ} \mathrm{C}$ ниже, чем температура восстановления без содовой смеси. Кроме того, время восстановления сокращается на $20 \%$. В случае смесей, содержащих более $3 \%$ соды, последний минимум на кривых ДТА при $1100^{\circ} \mathrm{C}$ объясняется вторичными твердофазными реакциями:

$$
\begin{gathered}
\mathrm{Na}_{2} \mathrm{SiO}_{3}+\mathrm{Na}_{2} \mathrm{Al}_{2} \mathrm{O}_{4} \rightarrow 2 \mathrm{Na}_{2} \mathrm{O} . \mathrm{Al}_{2} \mathrm{O}_{3} \cdot \mathrm{SiO}_{2}, \\
3 \mathrm{CaO} . \mathrm{Al}_{2} \mathrm{O}_{3}+2 \mathrm{Al}_{2} \mathrm{O}_{3} \rightarrow\left(\mathrm{CaO} \cdot \mathrm{Al}_{2} \mathrm{O}_{3}\right) .
\end{gathered}
$$

Основное значение соды состоит в том, что она во время обжига шихты взаимодействует с примесями, находящимися в концентрате, образует растворимые и нерастворимые соединения в воде, которые легко удаляются при магнитной мокрой сепарации. 
Заключение. Таким образом, исследованы кинетика и механизм восстановления гематитовых концентратов с углеродом и карбонатом натрия. Согласно этому механизму, при содержании $10 \%$ соды резко ускоряется процесс восстановления, а углерод - лучший восстановитель для восстановления гематитовых концентратов. Сода активирует явление газификации углерода своими продуктами распада $\left(\mathrm{Na}_{2} \mathrm{CO}_{3} \rightarrow \mathrm{Na}_{2} \mathrm{O}+\mathrm{CO}_{2}\right)$, которые, сохраняя избыточную энергию, внедряются в кристаллическую решетку графита, способствуя ослаблению связей между базисными плоскостями.

Сода также влияет на магнетит, полученный в результате восстановления, на поверхности которого адсорбируются возбужденные молекулы $\mathrm{Na}_{2} \mathrm{O}$. В этом случае добавление соды к одновалентному металлу изменяет количество свободных электронов или отверстий, а следовательно, и реакционные свойства оксида.

Исследование проводилось в базовой научно-исследовательской лаборатории “Материаловедение и металлургия" Национального политехнического университета Армении.

\section{Литературы}

1. Геология Армянской СССР. Металлические полезные ископаемые. Том VI.- Ереван, 1967.- $174 \mathrm{c}$.

2. Агбалян С.Г., Апоян Т.Г. Особенности измельчения и обогащения гематитовых руд и выбор оптимальных режимов // Вестник Инженерной академии Армении.Ереван, 2006.- Т. 3, N 2.- С. 262-265.

3. Агбалян С.Г., Апоян Т.Г., Франгулян А.А., Казарян А.Н. Исследование процессов отжига гематитовых руд и силикатообразующих реакций // Известия НАН РА и ГИУА. Сер. ТН.- 2008.- Т. 61, N 1.- С. 18-25.

4. Апоян Т.Г. Разработка технологии получения железного порошка из гематитовых руд: Автореф. дис. ...к.т.н.- Ереван, 2008.- 17 с.

5. Юсфин Ю.С., Пашков Н.Ф. Металлургия железа: Учебник для вузов.- М.: ИКЦ Академкнига, 2007.- 464 с.

Поступила в редакиию 09.03.2021. Принята к опубликованию 21.05.2021. 


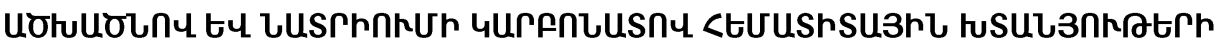

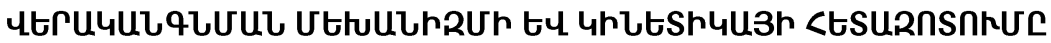

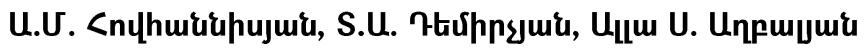

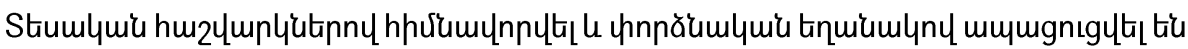

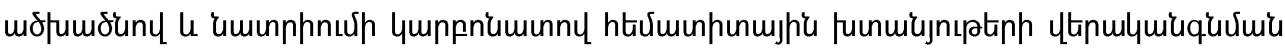

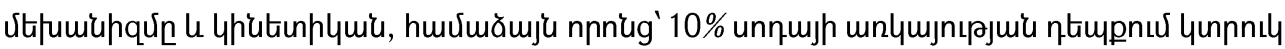

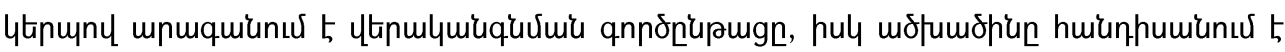

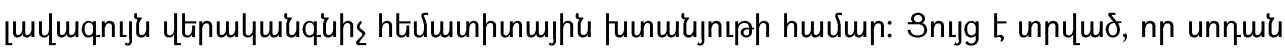

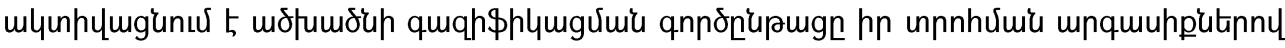

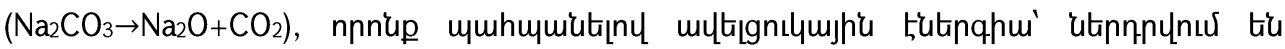

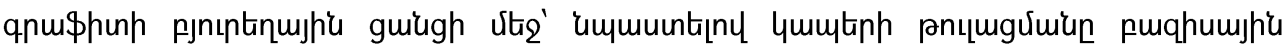

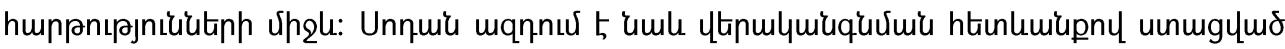

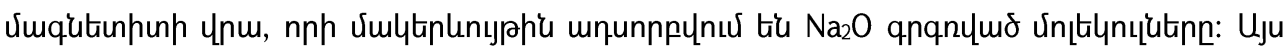

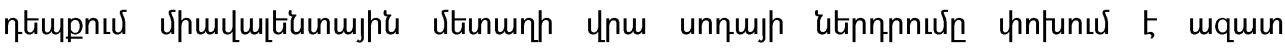

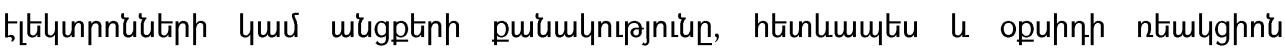
humulynıرnııun:

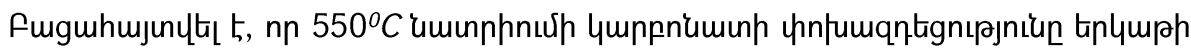

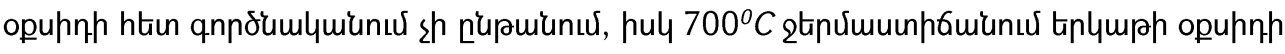

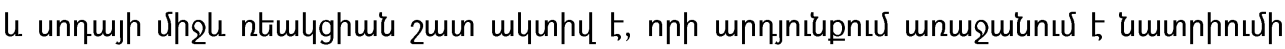

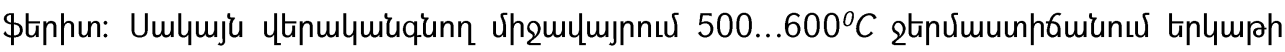



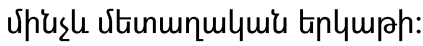

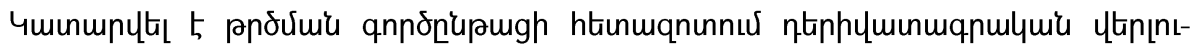



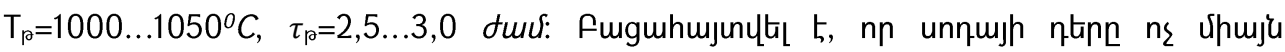



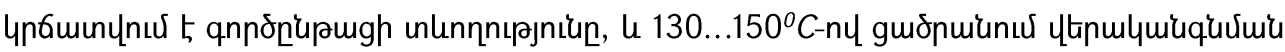

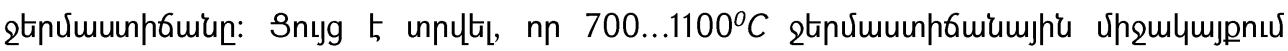

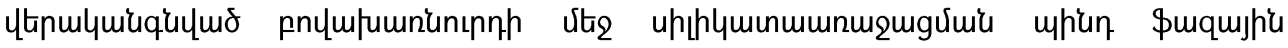

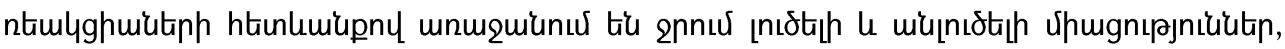

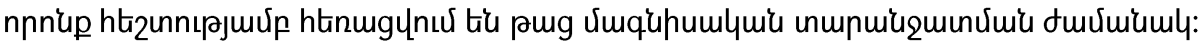

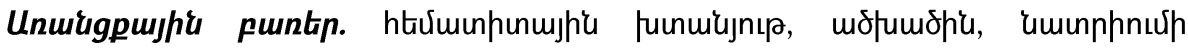

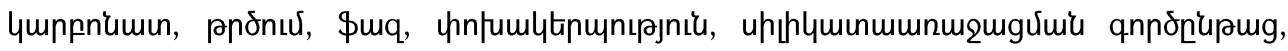
utinulquiuquinux: 


\section{INVESTIGATING THE MECHANISM AND KINETICS OF THE HEMATITE CONCENTRATE RESTORATION WITH CARBON AND SODIUM CARBONATE}

\section{A.M. Hovhannisyan, T.A. Demirchyan, Alla S. Aghbalyan}

The restoration mechanism and kinetics of hematite concentrates with carbon and sodium carbonate have been justified by theoretical calculations and proved by the exparimetal method. According to the described mechanism with the $10 \%$ sodium carbonate, the restoration process becomes significantly faster, while carbon is the best restorer for hematite concentrates. It is shown that sodium carbonate activates the process of carbon gasification with its partition effects $\left(\mathrm{Na}_{2} \mathrm{CO} 3 \mathrm{Na}_{2} \mathrm{O}+\mathrm{CO}_{2}\right)$, which maintain extra energy and are introduced into the graphite grid, thereby weakening the connections among the base planes. The sodium carbonate also has an effect on the magnetite that emerges as a result of restoration; the provoked $\mathrm{Na}_{2} \mathrm{O}$ molecules get adsorbed on its surface. In this case, the application of sodium carbonate on univalent metals changes the quantity of free electrons or passages and thereby the reaction property of the oxide.

It has been found that the interaction of $550^{\circ} \mathrm{C}$ sodium carbonate with iron oxide is practically non-existent, and at $700^{\circ} \mathrm{C}$, the reaction between iron oxide and soda is very active, resulting in the formation of sodium ferrite. However, at temperature of $500 \ldots 600^{\circ} \mathrm{C}$ in the restorative environment, the iron oxide is reduced to a lower oxide, and at higher temperatures - to a metal oxide.

The roasting process has been studied by the derivatographic analysis method, as a result of which we have been able to identify the optimal modes of roasting: $\operatorname{Tr}=1000 \ldots 1050^{\circ} \mathrm{C}, \mathrm{r}=2,5 \ldots 3,0$ hour. It has been established that the role of sodium carbonate is not only the intensification of silicate emergence and restoration, but also a $20 \%$ reduction in the duration of the process and a $130 \ldots 150^{\circ} \mathrm{C}$ decrease of the restoration temperature. It is shown that in the range of $700 \ldots 1100^{\circ} \mathrm{C}$, water solvable and unsolvable compounds are extracted in the restored mixture as a result of hard - phase reactions of silicate formation; the compounds are easily removed by wet magnetic partition.

Keywords: hematite concentrate, carbon, sodium carbonate, roasting, phase, transformation, silicate formation process, restoration. 